\title{
Ecological analysis of the association between high-risk population parameters and HIV prevalence among pregnant women enrolled in sentinel surveillance in four southern India states
}

\author{
Michel Alary, ${ }^{1}$ A A Jayachandran, ${ }^{2}$ Catherine M Lowndes, ${ }^{3}$ Jan Bradley, ${ }^{2}$ \\ Eric Demers, ${ }^{1}$ Rajatashuvra Adhikary, ${ }^{4}$ Mandar K Mainkar ${ }^{5}$
}

1 URESP, Centre de recherche FRSQ du Centre de recherche du CHA universitaire de Québec Québec, Canada ${ }^{2}$ CHARME-India Project, Bangalore, India ${ }^{3} \mathrm{Health}$ Protection Agency, London, UK ${ }^{4}$ Family Health International, New Delhi, India ${ }^{5}$ National AIDS Research Institute, Pune, India

\section{Correspondence to} Dr Michel Alary, Centre hospitalier affilié universitaire de Québec, 1050 Chemin Ste-Foy, Québec, Qc, G1S 4L8, Canada; malary@uresp.ulaval.ca

Accepted 27 September 2009

This paper is freely available online under the BMJ Journals unlocked scheme, see http://sti. bmi.com/site/about/unlocked. xhtml

\section{ABSTRACT}

Background The HIV epidemic is very heterogeneous at the district level in the four Southern states of India most affected by the epidemic and where transmission is mainly heterosexual. The authors carried out an ecological study of the relationship between high-risk population parameters and HIV prevalence among pregnant women (ANC HIV prevalence).

Methods The data used in this study included: ANC HIV prevalence available from the National AIDS Control Organization (dependent variable); data on prevalence of HIV and other sexually transmitted infections among female sex workers (FSWs), their clients and high-risk men who have sex with men (HR-MSM) from studies carried out in 24 districts under Avahan; data on clients' volume reported by FSWs and on the size estimates of FSWs and HR-MSM in each district; and census data. The latter two sets of data were used to estimate the percentage of female (male) adults who are FSWs (HRMSM). The latter was also multiplied by HIV prevalence in FSWs (HR-MSM) to obtain the percentage of HIV-positive FSWs (HR-MSM) in the adult female (male) population. Linear regression was used for statistical analyses.

Results In univariate analyses, HIV ( $r=0.59, p=0.002)$ and HSV-2 ( $r=0.49, p=0.014)$ prevalence among FSWs and mean number of clients in the last week reported by FSWs $(r=0.43, p=0.036)$ were significant predictors of ANC HIV prevalence. In multivariate analysis, only FSW HIV prevalence remained significant.

Conclusions This ecological study suggests that there is a link between HIV prevalence among FSWs and the spread of HIV to the general population in Southern India. Such an observation supports the rationale of interventions targeted at the sex industry.

\section{INTRODUCTION}

In concentrated HIV epidemics, like those prevailing in South Asia, it is widely accepted that preventive interventions targeted at the most at-risk populations, like female sex workers (FSWs), are key to the control of the epidemic. However, evidence for the overall impact of such interventions at the population level in South Asia mainly comes so far from mathematical modelling studies. ${ }^{12}$

One of the premises to such potential for impact of targeted interventions is that there should be a relationship between some high-risk population parameters (prevalence of HIV and other sexually transmitted infections (STIs), population size) and
HIV prevalence in the general population. Despite this, very few empirical studies have so far addressed this issue. In one study that used broad international comparisons across 77 countries and vague estimates of the population size of FSWs, Talbott found that both HIV prevalence among FSWs (based on data available from the US Census Bureau $^{3}$ ) and the proportion of FSWs among the general population of women predicted HIV prevalence in the general adult population (using UNAIDS estimates) at the country level. ${ }^{4}$

Avahan, the India AIDS initiative of the Bill \& Melinda Gates Foundation, is a large HIV prevention programme targeting FSWs, their clients, highrisk men who have sex with men (HR-MSM) and injection drug users in the six Indian states most affected by HIV. ${ }^{5}$ In the context of its evaluation, a large amount of data is collected on HIV and STI prevalence in these high-risk populations, for which district-specific size estimates are also available from programme implementation activities. We took this opportunity to carry out an ecological analysis of the relationship between high-risk population parameters and HIV prevalence among pregnant women enrolled in the sentinel surveillance system (ANC HIV prevalence) in the states of Andhra Pradesh, Karnataka, Maharashtra and Tamil Nadu in southern India, where heterosexual transmission of HIV is predominant. ${ }^{6}$

\section{METHODS \\ Independent variables}

Data from a cross-sectional survey termed the integrated biological and behavioural assessment (IBBA) were available for FSWs in 24 districts, and for their clients and HR-MSM in 16 districts. ${ }^{7}$ Most of these surveys were carried out in 2006, but some of them were conducted in 2004, 2005 and 2007 From these surveys, we used as independent variables the prevalence of HIV, gonorrhoea $(\mathrm{Ng})$, chlamydia (Ct), syphilis, any curable STI (defined as any of $\mathrm{Ng}, \mathrm{Ct}$ or syphilis) and herpes simplex type 2 (HSV-2) antibodies.

The other independent variables were the size estimates of the FSW, clients and HR-MSM populations. For FSWs and HR-MSM, these size estimates were obtained from the Avahan programme in each district and represent estimates from both the Avahan programme and Government of India. The methods used to obtain these estimates are described in detail elsewhere. ${ }^{8}$ Briefly, programme 
implementers used variations of a nonmathematical method that involved a combination of geographic and social mapping combined with the iterative, intensive use of Delphi techniques with different key informants for FSW and HR-MSM population size estimation. The size estimates were used as absolute numbers and also expressed as a proportion of FSWs among adult women (and of HR-MSM among adult men), by dividing the absolute numbers by population data based on the 2001 Census of India. ${ }^{9}$ We also defined independent variables on the proportion of HIV-positive FSWs (HR-MSM) among the total adult population of women (men) by multiplying the proportion of FSWs (HR-MSM) among adult women (men) by HIV prevalence in FSWs (HR-MSM). For clients of FSWs, we used for each district the mean number of clients in the last week as reported by the FSWs in the IBBA. We also computed the total number of clients' visits to FSWs in the last week by multiplying this mean by the FSW size estimate. Finally, we roughly estimated the proportion of the adult male population who were clients of FSWs in the last week by dividing the latter figure by the total adult male population-based on the 2001 Census of India. ${ }^{9}$

All independent variables concerned urban areas only because Avahan is essentially an urban intervention, resulting in the collection of prevalence and size estimates data only for urban areas of each district. There was one exception to this: Belgaum district which is one of the six districts in northern Karnataka and southern Maharashtra with high number of devadasi FSWs, involved in a form of traditional sex work, ${ }^{10}$ and part of CORRIDOR, a special Avahan programme that covers both urban and rural areas and for which size estimates were available for the whole district.

Three districts had more than one IBBA survey among FSWs. In this case, the HIV and STI prevalence figures for FSWs in the district were computed using a weighted average of both surveys. One of the HR-MSM IBBA surveys was carried out over two different districts. In this case, the population size estimates of the two districts were combined for the analysis.

Tables 1-3 show the parameter values for each district for FSWs, their clients and HR-MSM, respectively.

\section{Dependent variable}

Because of the small district-level sample size of the yearly sentinel surveillance surveys and the time span over which the IBBA surveys were carried out, the ANC HIV prevalence figure used as the dependent variable was the mean of the prevalence found in the sentinel surveillance from 2004 to 2007 (4 years) in each district.

Table 1 HIV/STI prevalence among female sex workers (FSWs) in round 1 integrated biological and behavioural assessment and FSW size estimates versus HIV prevalence among urban ANC women

\begin{tabular}{|c|c|c|c|c|c|c|c|c|c|c|}
\hline & $\begin{array}{l}\text { ANC HIV } \\
\text { prevalence* }\end{array}$ & HIV & Syphilis & Gonorrhoea & Chlamydia & $\begin{array}{l}\text { Any } \\
\text { STI }\end{array}$ & HSV-2 & $\begin{array}{l}\text { FSW } \\
\text { population } \\
\text { size } \\
\text { estimate }\end{array}$ & $\begin{array}{l}\text { Percentage } \\
\text { of FSW in } \\
\text { female } \\
\text { population } †\end{array}$ & $\begin{array}{l}\text { Percentage } \\
\text { HIV+ FSW } \\
\text { in female } \\
\text { population } \ddagger\end{array}$ \\
\hline \multicolumn{11}{|l|}{ Andhra Pradesh } \\
\hline Chitoor & 0.94 & 8.0 & 10.3 & 2.5 & 3.1 & 14.4 & 80.8 & 7856 & 3.43 & 0.27 \\
\hline East Godavari & 2.25 & 26.3 & 15.0 & 1.2 & 3.2 & 18.9 & 87.4 & 7238 & 2.18 & 0.57 \\
\hline Guntur & 2.63 & 21.3 & 8.6 & 1.3 & 1.7 & 11.1 & 85.4 & 10372 & 2.81 & 0.60 \\
\hline Hyderabad & 1.50 & 14.3 & 17.4 & 6.4 & 6.5 & 24.1 & 79.8 & 7496 & 0.71 & 0.10 \\
\hline Karim Nagar & 1.81 & 21.1 & 6.4 & 1.6 & 3.0 & 10.2 & 74.2 & 2470 & 1.29 & 0.27 \\
\hline Prakasam & 2.82 & 11.1 & 5.2 & 0.2 & 3.4 & 7.6 & 64.6 & 3087 & 2.32 & 0.26 \\
\hline Visakhapatnam & 1.19 & 14.2 & 7.0 & 1.4 & 3.6 & 11.2 & 58.6 & 4234 & 0.94 & 0.13 \\
\hline Warangal & 1.56 & 10.8 & 10.2 & 1.9 & 2.9 & 12.5 & 55.7 & 3493 & 1.99 & 0.21 \\
\hline \multicolumn{11}{|l|}{ Karnataka } \\
\hline Bangalore Urban§ & 1.44 & 12.7 & 12.6 & 3.6 & 6.5 & 19.4 & 68.6 & 24301 & 1.48 & 0.19 \\
\hline Belgaum 9 & 3.25 & 33.9 & 8.0 & 4.7 & 6.5 & 14.4 & 83.9 & $9566^{* *}$ & $0.91 \dagger \dagger$ & 0.31 \\
\hline Bellary & 0.69 & 15.7 & 5.2 & 2.7 & 4.1 & 11.0 & 70.8 & 3852 & 2.05 & 0.32 \\
\hline Mysore $\neq \ddagger$ & 2.00 & 26.1 & 24.9 & 5.4 & 10.8 & 33.6 & 64.4 & 1950 & 0.69 & 0.18 \\
\hline Shimoga & 0.69 & 9.7 & 4.0 & 1.3 & 5.6 & 10.6 & 59.6 & 1587 & 0.97 & 0.09 \\
\hline \multicolumn{11}{|l|}{ Maharashtra } \\
\hline Kolhapur & 2.13 & 33.0 & 27.0 & 4.3 & 5.2 & 30.4 & 83.3 & 1019 & 0.35 & 0.12 \\
\hline Mumbai§§ & 1.16 & 20.3 & 10.4 & 6.6 & 6.9 & 20.3 & 70.9 & 32575 & 1.05 & 0.21 \\
\hline Parbhani & 0.63 & 16.1 & 11.5 & 1.9 & 2.0 & 13.2 & 52.2 & 2135 & 1.85 & 0.30 \\
\hline Pune§§ & 2.33 & 38.0 & 35.5 & 6.2 & 6.9 & 44.1 & 87.1 & 7223 & 0.63 & 0.24 \\
\hline Thane§§ & 1.50 & 12.9 & 6.9 & 2.9 & 8.9 & 16.7 & 43.2 & 17254 & 1.11 & 0.14 \\
\hline Yevatmal & 1.31 & 37.3 & 51.0 & 4.6 & 8.5 & 57.5 & 100.0 & 969 & 0.80 & 0.30 \\
\hline \multicolumn{11}{|l|}{ Tamil Nadu } \\
\hline Chennai & 0.25 & 2.2 & 11.3 & 0.3 & 1.8 & 12.6 & 34.6 & 17392 & 1.41 & 0.03 \\
\hline Coimbatore & 0.57 & 6.3 & 11.9 & 2.2 & 2.4 & 14.5 & 58.9 & 1593 & 0.19 & 0.01 \\
\hline Dharmapuri & 0.69 & 12.4 & 10.7 & 0.5 & 4.3 & 14.0 & 72.1 & 4802 & 3.79 & 0.47 \\
\hline Madurai & 0.50 & 4.3 & 11.1 & 0.0 & 0.9 & 11.9 & 52.2 & 7000 & 1.69 & 0.07 \\
\hline Salem & 2.50 & 12.5 & 7.5 & 1.7 & 3.7 & 10.8 & 62.9 & 5130 & 1.32 & 0.16 \\
\hline
\end{tabular}

*Mean of yearly prevalence from 2004 to 2007

$+($ FSW estimate/urban female $15-49) \times 100$, Census 2001

$\ddagger$ Percentage of HIV-positive FSW in the total adult (15-49) female population.

§FSW STI prevalence weighted for Bangalore Urban: weight $=75 \%$ for Bangalore U-SB and $25 \%$ for Bangalore U-BB.

qANC prevalence (mean of rural+urban).

**Size estimate in both urban and rural areas because Belgaum is a CORRIDOR district (FSW intervention in both rural and urban areas).

†+(FSW estimate/rural+urban female 15-49) $\times 100$, Census 2001 (CORRIDOR district).

$\ddagger \ddagger F S W$ HIV/STI prevalence of Mysore IBBA round 1.

$\S \S F S W$ HIV/STI prevalence weighted by the number of respondents in each FSW category. 
Table 2 HIV/STI prevalence among clients of female sex workers (FSWs) in round 1 integrated biological and behavioural assessment and clients volume estimates

\begin{tabular}{|c|c|c|c|c|c|c|c|c|c|}
\hline & HIV & Syphilis & Gonorrhoea & Chlamydia & $\begin{array}{l}\text { Any } \\
\text { STI }\end{array}$ & HSV-2 & $\begin{array}{l}\text { Mean } \\
\text { no of } \\
\text { clients* }\end{array}$ & $\begin{array}{l}\text { Total } \\
\text { no of } \\
\text { client's } \\
\text { visits } †\end{array}$ & $\begin{array}{l}\text { Percentage } \\
\text { of clients in } \\
\text { male } \\
\text { population } \ddagger\end{array}$ \\
\hline \multicolumn{10}{|l|}{ Andhra Pradesh } \\
\hline Chitoor & ND & ND & ND & ND & ND & ND & 10.1 & 79673 & 33.5 \\
\hline East Godavari & 8.3 & 4.8 & 0.0 & 0.9 & 5.5 & 44.8 & 10.9 & 79130 & 23.8 \\
\hline Guntur & 6.6 & 10.1 & 0.0 & 0.8 & 10.6 & 69.2 & 11.4 & 118267 & 31.7 \\
\hline Hyderabad & 2.4 & 3.1 & 0.0 & 2.1 & 4.4 & 27.4 & 5.4 & 40347 & 3.6 \\
\hline Karim Nagar & ND & ND & ND & ND & ND & ND & 5.9 & 14618 & 7.4 \\
\hline Prakasam & ND & ND & ND & ND & ND & ND & 12.1 & 37368 & 27.4 \\
\hline Visakhapatnam & 8.0 & 3.4 & 1.3 & 0.4 & 4.4 & 78.0 & 11.3 & 47871 & 10.2 \\
\hline Warangal & 6.7 & 5.5 & 1.6 & 0.4 & 6.7 & 18.9 & 7.0 & 24382 & 13.4 \\
\hline \multicolumn{10}{|l|}{ Karnataka } \\
\hline Bangalore Urban & 2.4 & 3.8 & 0.6 & 3.0 & 6.9 & NA & 9.5 & 231345 & 12.5 \\
\hline Belgaum & 6.2 & 4.2 & 0.0 & 1.4 & 5.1 & 27.9 & 15.7 & 150175 & 13.5 \\
\hline Bellary & 6.0 & 5.8 & 0.9 & 1.8 & 7.2 & 26.6 & 11.7 & 45211 & 22.7 \\
\hline Mysore & ND & ND & ND & ND & ND & ND & 7.9 & 15490 & 5.3 \\
\hline Shimoga & 3.0 & 3.1 & 0.8 & 0.0 & 4.2 & 25.7 & 5.2 & 8265 & 4.9 \\
\hline \multicolumn{10}{|l|}{ Maharashtra } \\
\hline Kolhapur & ND & ND & ND & ND & ND & ND & 12.1 & 12298 & 4.0 \\
\hline Mumbai & 9.1 & 3.9 & 0.9 & 4.5 & & 26.8 & 10.7 & 348492 & 8.5 \\
\hline Parbhani & 6.4 & 4.0 & 0.7 & 3.6 & 7.9 & 13.7 & 8.8 & 18807 & 15.1 \\
\hline Pune & 6.0 & 6.0 & 0.1 & 3.0 & 7.8 & 19.0 & 10.9 & 78939 & 6.1 \\
\hline Thane & ND & ND & ND & ND & ND & ND & 8.4 & 144794 & 7.3 \\
\hline Yevatmal & 10.9 & 7.8 & 0.9 & 1.6 & 9.7 & 21.1 & 18.0 & 17408 & 13.4 \\
\hline \multicolumn{10}{|l|}{ Tamil Nadu } \\
\hline Chennai & 2.0 & 4.7 & 0.0 & 1.2 & 5.9 & 19.6 & 5.6 & 97808 & 7.6 \\
\hline Coimbature & ND & ND & ND & ND & ND & ND & 6.1 & 9648 & 1.1 \\
\hline Dharmapuri & ND & ND & ND & ND & ND & ND & 10.4 & 50039 & 37.6 \\
\hline Madurai & 2.5 & 3.5 & 0.0 & 0.0 & 3.5 & 10.2 & 5.6 & 39272 & 9.4 \\
\hline Salem & 4.2 & 3.5 & 0.0 & 1.0 & 4.3 & 22.3 & 7.5 & 38647 & 9.6 \\
\hline
\end{tabular}

*Mean number of clients in the last week as reported by FSWs.

†Total number of clients' visits to FSWs in the last week obtained by multiplying the mean number of clients in the last week by the Avahan FSW size estimate.

‡Estimate obtained for a 1-week period only under the assumption that clients only visit FSWs once in a given week and by dividing the total number of clients visits to FSWs in the last week by the urban 15-49 male population (except for Belgaum where the population of the whole district was included in the denominator).

NA, not available; ND, no study carried out among clients in these districts.

As we did for the independent variables, we considered ANC HIV prevalence for urban areas, with the exception of Belgaum, where the overall district prevalence was used. In the analyses using HR-MSM parameters, for the data collected over two different districts, the ANC HIV prevalence was estimated by weighting the mean 2004-07 prevalence according to the relative population size of women aged 15-49 in the two districts. Tables 1 also show the actual values of the dependent variable used in the analyses involving variables on FSWs and their clients, whereas table 3 shows the corresponding values for analyses involving HR-MSM parameters.

\section{Statistical analyses}

We carried out univariate linear regression relating each of the independent variables to ANC HIV prevalence at the district level. There were 24 observations for all the analyses involving FSW and client volume parameters, whereas the corresponding number was 16 for the two other populations. All independent variables with a $\mathrm{p}$ value $<0.10$ were then entered in a multivariate linear regression model.

\section{RESULTS}

Table 4 shows the results of the univariate linear regression analyses. HIV and HSV-2 prevalence among FSWs as well as the mean number of clients in the last week reported by the FSWs were significantly associated with ANC HIV prevalence ( $\mathrm{p}$ values of $0.0022,0.0142$ and 0.0362 , respectively). Figure $1 \mathrm{~A}$ shows the scatter plot and least-square regression line for the relation between ANC HIV prevalence and FSW HIV prevalence at the district level, whereas figure 1B,C shows similar graphs for FSW HSV-2 prevalence and mean number of clients. The proportion of the variance in ANC HIV prevalence explained by each of these three univariate models $\left(\mathrm{R}^{2}\right)$ was $0.3535,0.2437$ and 0.1844 , respectively. There was also a borderline significant association $(p=0.0673)$ between the proportion of HIV-positive FSWs in the total adult female population (figure $1 D$ ), with an $R^{2}$ of 0.1441 .

As HIV and HSV-2 prevalence among FSWs were strongly correlated $(r=0.7524, p<0.0001)$, we excluded the latter from multivariate analysis. In the model, the beta coefficients were 0.04473 for HIV prevalence among FSWs, -0.01108 for the mean number of clients in the last week reported by the FSWs, and 1.05365 for the proportion of HIV-positive FSWs in the total adult female population, with $p$ values of $0.033,0.867$ and 0.355 , respectively. The $\mathrm{R}^{2}$ was only slightly higher than for the univariate model with HIV prevalence in FSWs as the dependent variable, at 0.3821 , and the addition of the two other variables to the model was not statistically significant $(p=0.636)$. To explore why the association between the mean number of clients and ANC HIV prevalence went from a positive significant correlation in the univariate analysis to a negative non-significant association in the multivariate analysis, we examined the relationship 
Table 3 HIV/STI prevalence among high-risk men who have sex with men (HR-MSM) in round 1 integrated biological and behavioural assessment and HR-MSM size estimates versus HIV prevalence among urban ANC women

\begin{tabular}{|c|c|c|c|c|c|c|c|c|c|c|}
\hline & $\begin{array}{l}\text { ANC HIV } \\
\text { prevalence* }\end{array}$ & HIV & Syphilis & Gonorrhoea & Chlamydia & $\begin{array}{l}\text { Any } \\
\text { STI }\end{array}$ & HSV-2 & $\begin{array}{l}\text { HR-MSM } \\
\text { population } \\
\text { size } \\
\text { estimate }\end{array}$ & $\begin{array}{l}\text { Percentage } \\
\text { of HR-MSM } \\
\text { in male } \\
\text { population } \dagger\end{array}$ & $\begin{array}{l}\text { Percentage } \\
\text { HIV+ HR- } \\
\text { MSM in } \\
\text { male } \\
\text { population }\end{array}$ \\
\hline East Godavari & 2.25 & 22.2 & 13.0 & 0.0 & 1.0 & 13.9 & 77.7 & 1825 & 0.55 & 0.12 \\
\hline Guntur & 2.63 & 13.1 & 3.5 & 0.4 & 1.4 & 5.3 & 29.1 & 2770 & 0.74 & 0.10 \\
\hline Hyderabad & 1.50 & 24.7 & 15.7 & 0.9 & 2.0 & 18.3 & 69.0 & 5030 & 0.45 & 0.11 \\
\hline \multicolumn{11}{|l|}{ Karnataka } \\
\hline Bangalore Urban & 1.44 & 18.9 & 11.1 & 0.9 & 3.4 & 12.0 & 34.2 & 5461 & 0.29 & 0.06 \\
\hline Belgaum $\neq$ & 3.25 & 10.6 & 10.3 & 0.0 & 0.9 & 9.2 & 49.1 & 2026 & $0.18 \S$ & 0.02 \\
\hline Bellary & 0.69 & 30.7 & 22.7 & 0.9 & 2.3 & 20.9 & 59.2 & 551 & 0.28 & 0.08 \\
\hline Mysore & 2.00 & 23.0 & 23.0 & 1.0 & 0.0 & 24.0 & 62.0 & 760 & 0.26 & 0.06 \\
\hline \multicolumn{11}{|l|}{ Tamil Nadu } \\
\hline Chennai & 0.25 & 4.8 & 12.9 & 0.3 & 0.7 & 13.8 & 31.9 & 9171 & 0.71 & 0.03 \\
\hline Coimbatore & 0.57 & 6.5 & 14.5 & 0.0 & 0.8 & 15.1 & 27.3 & 1539 & 0.18 & 0.01 \\
\hline Madurai & 0.50 & 22.3 & 17.8 & 0.0 & 1.1 & 18.8 & 40.3 & 1352 & 0.32 & 0.07 \\
\hline Salem & 2.50 & 5.5 & 12.2 & 0.0 & 0.3 & 12.4 & 14.7 & 2458 & 0.61 & 0.03 \\
\hline
\end{tabular}

*Mean of yearly prevalence from 2004 to 2007

t(HR-MSM estimate/urban male 15-49)×100, Census 2001.

$\ddagger$ ANC prevalence (mean of rural + urban).

$\S($ HR-MSM estimate/rural+urban male 15-49) $\times 100$, Census 2001 (CORRIDOR district).

वThe ANC prevalence is weighted by the total population for the 15-49 age group in Mumbai and Thane (Census 2001).

between HIV FSW prevalence and clients parameters and found that it was indeed significantly correlated with the mean number of clients in the last week $(r=0.6660, p=0.0002)$, and also with HIV prevalence among clients $(r=0.6658, p=0.0049)$. Given these observations, our final model for predicting ANC HIV prevalence, with the set of independent variables considered, is the univariate analysis with FSW HIV prevalence as the independent variable.

\section{DISCUSSION}

In one of the first studies on this issue, we found a significant association between HIV prevalence among FSWs and HIV prevalence among pregnant women at the ecological level of 24 districts over four Southern states of India. We also found an association between HSV-2 prevalence among FSWs and ANC HIV prevalence, but it was entirely due to a very strong ecological association between HIV and HSV-2 prevalence among FSWs, adding another piece of evidence supporting the strong biological interaction between HIV and HSV-2. ${ }^{11-15}$ It also appears that the association we found between the clients' volume reported by FSWs and ANC HIV prevalence was mediated by the association between the former and HIV prevalence among FSWs.

Our results are partially in concordance with those of Talbott, who also found an association between FSW HIV prevalence estimates and UNAIDS HIV estimates for the general adult population across 77 countries. ${ }^{4}$ However, contrary to Talbott, we did not find an association between FSW population size estimates and HIV prevalence in the general population (in our study, HIV prevalence among pregnant women was used as proxy for general population prevalence). This study was however highly criticised for the vagueness of the country data on numbers of FSWs, ${ }^{16}$ even by the authors who published the data on FSW population size estimates, ${ }^{17}$ as well as for the positions taken by the non-governmental association chaired by the author on sex work and HIV ${ }^{18}$ that could have influenced choices in his analyses, and the strength of his conclusions, given the limitations of ecological analyses. ${ }^{19}$

Under certain circumstances, the ecological association between ANC and FSW HIV prevalence may not be due to issues related to HIV transmission dynamics. In particular, this would not be the case if a high proportion of HIV-infected pregnant women are or used to be FSWs, and if this proportion is higher in districts with high ANC HIV prevalence. Unfortunately, it was not possible to formally analyse this possibility because data on FSW fertility and attendance to ANC services were not available for most of the studied districts, and that it is not possible to assume that the two latter parameters are similar in FSWs and other women. However, in three districts (Belgaum, Bellary and Shimoga), such data were collected in surveys carried out at a later date than those used for our ecological analysis. Using these data in combination with data on the female population size from the census of India, ${ }^{9}$ on pregnancy and ANC attendance history from the reproductive and child health district level household survey carried out in India from 2002 to $2004^{20}$ as well as ANC and FSW HIV prevalence presented in table 1 , it can be roughly estimated that between $0.6 \%$ (Shimoga) and $0.9 \%$ (Bellary) of pregnant women attending ANC services in a given year are FSWs, but that between $8 \%$ (both Belgaum and Shimoga) and 21\% (Bellary) of HIV-positive women in these settings are FSWs. Although the latter proportions can be considered as quite high, they are similar or even lower in the district with the highest ANC HIV prevalence (Belgaum at 3.25\%) compared with the two others (both Shimoga and Bellary at $0.69 \%$ ). Under these conditions, it is thus very unlikely that the association we observed between 
Table 4 Univariate linear regression with HIV prevalence in the ANC population as the dependent variable

\begin{tabular}{|c|c|c|}
\hline Independent variables & Beta & p Value \\
\hline \multicolumn{3}{|l|}{ FSW } \\
\hline HIV & 0.04822 & 0.0022 \\
\hline Syphilis & 0.00808 & 0.6213 \\
\hline Gonorrhoea & 0.10424 & 0.2273 \\
\hline Chlamydia & 0.08176 & 0.2368 \\
\hline Any STls & 0.00953 & 0.5228 \\
\hline HSV2 & 0.02626 & 0.0142 \\
\hline Avahan FSW size estimate & -0.00000682 & 0.7635 \\
\hline Percentage of FSW in female population & -0.08735 & 0.6523 \\
\hline $\begin{array}{l}\text { Percentage HIV+ FSW in female } \\
\text { population }\end{array}$ & 2.0804 & 0.0673 \\
\hline \multicolumn{3}{|l|}{ Clients of FSW } \\
\hline HIV & 0.08422 & 0.3327 \\
\hline Syphilis & 0.14085 & 0.2502 \\
\hline Gonorrhoea & -0.60925 & 0.1510 \\
\hline Chlamydia & -0.01907 & 0.9155 \\
\hline Any STIs & 0.09778 & 0.4153 \\
\hline HSV2 & 0.01426 & 0.2685 \\
\hline Mean no of clients last week* & 0.10869 & 0.0362 \\
\hline Total no of visits to FSW last week & 0.00000094 & 0.6715 \\
\hline $\begin{array}{l}\text { Percentage of clients in male population } \\
\text { last week }\end{array}$ & 0.00729 & 0.6751 \\
\hline \multicolumn{3}{|l|}{ HR-MSM } \\
\hline HIV & -0.00112 & 0.9722 \\
\hline Syphilis & -0.04175 & 0.3616 \\
\hline Gonorrhoea & -0.15022 & 0.8323 \\
\hline Chlamydia & -0.11163 & 0.6506 \\
\hline Any STIs & -0.04872 & 0.3225 \\
\hline HSV2 & 0.000658 & 0.9633 \\
\hline Avahan HR-MSM size estimate & -0.00002466 & 0.6332 \\
\hline $\begin{array}{l}\text { Percentage of HR-MSM in male } \\
\text { population }\end{array}$ & 0.67763 & 0.6212 \\
\hline $\begin{array}{l}\text { Percentage HIV+ HR-MSM in male } \\
\text { population }\end{array}$ & 4.1865 & 0.5719 \\
\hline
\end{tabular}

${ }^{*}$ As reported by female sex workers (FSWs).

HSV-2, herpes simplex type 2.

ANC and FSW HIV prevalence could be due to a higher proportion of FSWs among HIV-infected pregnant women in districts with a high ANC HIV prevalence compared with those with a lower one.

There are several possible reasons why we did not find an association between HIV prevalence in pregnant women and the FSW population size estimates. First, such estimates are very difficult to make, as there is no standard method for it and that the universe of sex work may not be even defined the same way in different studies. ${ }^{17}$ Furthermore, some segments of the FSW population are more difficult to capture than others (overt vs hidden FSWs), and the ability to capture them may vary from one site to the other. Second, there was no standardisation across Avahan districts for the methods used for size estimates. ${ }^{21}$ Third, even in the presence of valid estimates, FSW population size per se may not be a key variable for the heterosexual spread of HIV to the general population. Indeed, it may well be that the total number of commercial sex acts and the nature of the sexual networks involved are more important. In addition, a small number of high volume FSWs with high HIV prevalence may contribute more to the HIV spread than a larger number of FSWs with lower HIV prevalence and smaller number of clients in environments where the demand for commercial sex is similar, because the proportion of commercial sex acts involving an HIVpositive FSW will be larger in the first scenario, thus leading to more transmission events to women of the general population through the clients bridge. Nevertheless, we found a borderline significant univariate association between the proportion of HIVpositive FSWs in the total adult female population and ANC HIV prevalence, thus suggesting a role for the size of the HIV-infected FSW population in HIV spread to the general population, as well as possible differential use of commercial sex services across the studied districts. Finally, as there has been a reported decline over time in ANC HIV prevalence in the Southern states of India that was somewhat differential between the states and widely attributed to interventions targeting $\mathrm{FSWs}^{22}$ it is also possible that our study comes too late in the course of the HIV epidemic in India to be able to identify the link between number of FSWs and HIV prevalence in the general population, that may have been present before the implementation of preventive interventions targeting FSWs.

Surprisingly as this population constitutes the transmission link between FSWs and women of the general population, ${ }^{23} 24$ we did not find any association between ANC HIV prevalence and the independent variables related to clients of FSWs in the multivariate analysis. However, the observations that the positive univariate association between ANC HIV prevalence and clients' volume per FSW appeared to be mediated by the association between the latter and FSW HIV prevalence (such association was also found in an analysis of the same data at the individual level ${ }^{25}$ ) and that HIV prevalence among both FSWs and their clients were significantly correlated, support the third hypothesis mentioned above to explain the lack of association between FSW size estimates and ANC HIV prevalence. The lack of association between our other clients' volume estimates and ANC HIV prevalence could also be due to the uncertainties in the estimation of the size of the FSW population (see above) on which they were all based. The lack of association between HIV/ STI prevalence among clients and our main dependent variable could be due to lack of power, as these analyses used only 16 districts. It could also be due to the fact that it proved very difficult to recruit representative samples of clients in the IBBA and that refusal rates were high at over $50 \%$ in most IBBA districts. ${ }^{7}$ These factors could indeed have led to biased HIV/STI prevalence estimates in this population, with even differential biases across the districts.

It is less surprising to see the absence of association between our dependent variable and HR-MSM parameters. Indeed, even if many of them also have sex with women, ${ }^{7}$ they may not play such a large role in HIV transmission to the general population in a context where heterosexual transmission is predominant. ${ }^{6}$ In addition, the definition of HR-MSM eligibility was not the same across all IBBA districts. As the sampling frame for the IBBA only included HR-MSM, it is also possible that other less homosexually active MSM constitute a more important bridging group for HIV transmission to the general population because they are more heterosexually active than HR-MSM. Finally, as for the clients of FSWs, there could have been a power issue.

In addition to the limitations mentioned above, our study may also have suffered from the problems inherent to ecological studies, including the ecological bias and lack of appropriate control for confounding. ${ }^{26}$ Nevertheless, ecological studies can be useful to generate hypotheses and sometimes, as, in the present study, they can be the only feasible approach to address certain research questions. In the field of HIV, ecological studies have been particularly useful to first identify the protective role of male circumcision, ${ }^{27} 28$ which was further confirmed by metaanalyses of numerous observational studies, ${ }^{29}$ and ultimately by clinical trials. $^{30-32}$ 

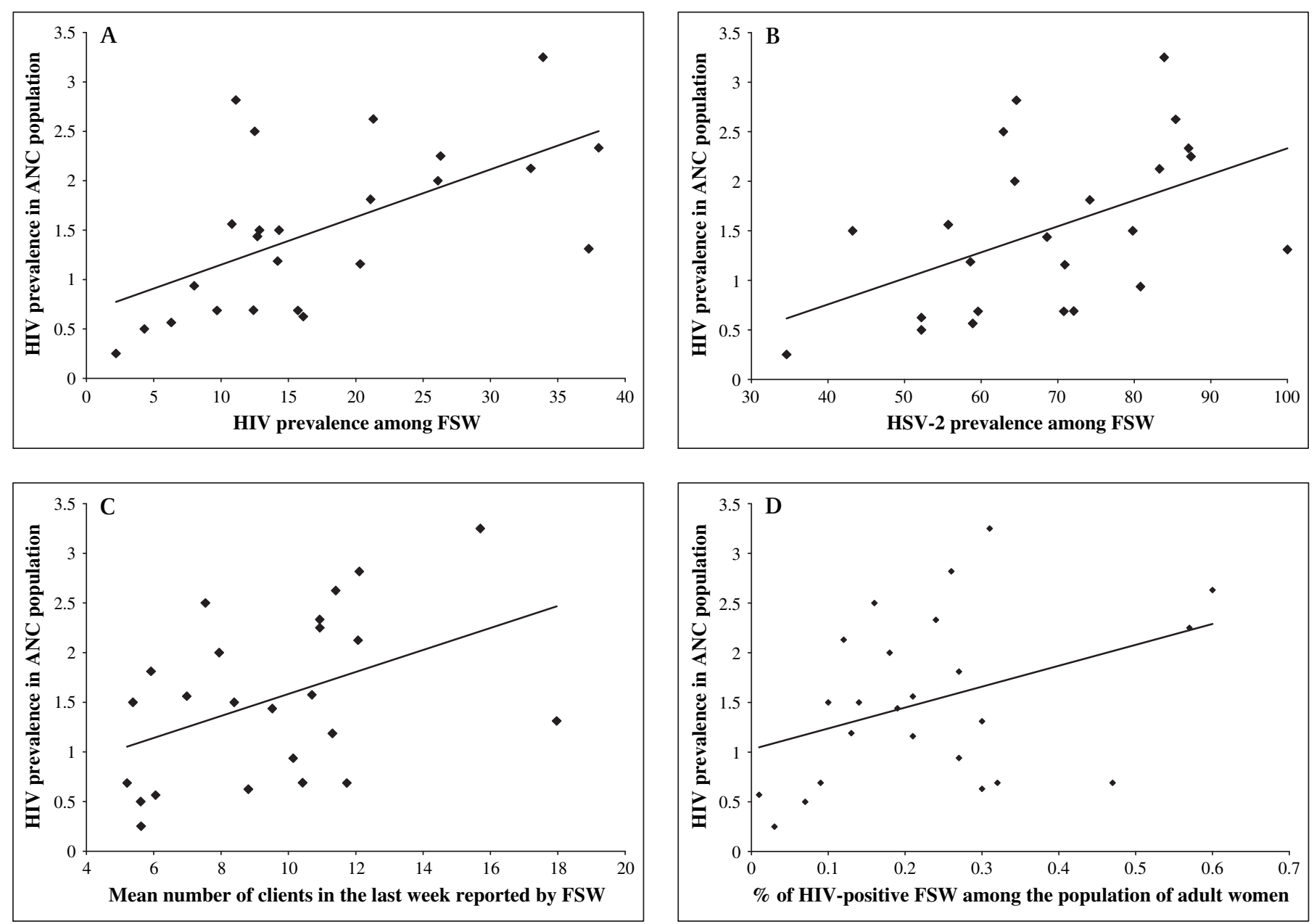

Figure 1 Scatter plot and predicted values according to univariate linear regression models relating HIV prevalence in the ANC population (dependent variable) and: (A) HIV prevalence among female sex workers (FSWs) $\left(r=0.5946 ; R^{2}=0.3535\right.$; HIV (ANC) $=0.66827+0.04822$ HIV (FSW)); (B) herpes simplex type 2 (HSV-2) prevalence among FSWs $\left(r=0.4937 ; R^{2}=0.2437\right.$; HIV $(A N C)=-0.29325+0.02626$ HSV-2 (FSW)); (C) mean number of clients in the last week reported by FSWs $\left(r=0.4294 ; R^{2}=0.1844\right.$; HIV $(A N C)=0.47883+0.10869$ (mean number of clients); (D) the proportion of HIV-positive FSWs among the adult female population $\left(r=0.3796 ; R^{2}=0.1441 ; \mathrm{HIV}(\mathrm{ANC})=1.02945+2.08035(\% \mathrm{HIV}+\mathrm{FSW}\right.$ in female population)), in 24 districts of Andhra Pradesh, Maharashtra, Tamil Nadu and Karnataka.

In conclusion, this study suggests that there is a link between HIV prevalence among FSWs and the spread of HIV to the general population in the Southern Indian states of Andhra Pradesh, Karnataka, Maharashtra and Tamil Nadu. Such an observation supports the rationale of interventions targeted at the commercial sex milieu, such as Avahan. Our results also underline the importance of developing and standardising improved methods for size estimates of the most at-risk populations in the context of concentrated HIV epidemics.

\section{Key messages}

- We found a significant ecological association between HIV prevalence among pregnant women enrolled in the sentinel surveillance system and HIV prevalence among female sex workers in 24 districts of four southern Indian states.

- This association may reflect the central role of female sex workers and their clients in the transmission dynamics of HIV to the general population.

- This observation supports the rationale of interventions targeted at the commercial sex milieu, such as Avahan.
Acknowledgements We thank the Avahan lead implementing partners, Family Health International, Hindustan Latex Family Planning Promotion Trust, International HIV/AIDS Alliance, Karnataka Health Promotion Trust (KHPT), Pathfinder International and Voluntary Health Services, for providing data on FSW and high-risk MSM population size estimates and KHPT for providing the HIV/STI prevalence data from the IBBA surveys carried out in Karnataka state. MA is a national researcher of the Fonds de la Recherche en Santé du Québec, Canada (grant no 8722).

Contributors MA designed the study, supervised the data analyses and wrote the manuscript. AAJ prepared the database for analysis by extracting data from different sources and contributed to the data analysis. CML contributed to the study design and provided extensive input to the preparation of the manuscript. JB contributed to the study design, supervised the data extraction and provided extensive input to the preparation of the manuscript. ED carried out most of the data analyses. RA contributed to the study design and provided the IBBA data used in this study for the districts in Andhra Pradesh, Maharashtra and Tamil Nadu. MKM contributed to the study design and provided the IBBA data used in this study for the districts in Andhra Pradesh, Maharashtra and Tamil Nadu. All the authors provided comments on initial versions of the manuscript and approved its final content.

Funding This research was funded by the Bill \& Melinda Gates Foundation. The views expressed herein are those of the authors and do not necessarily reflect the official policy or position of the Bill \& Melinda Gates Foundation.

\section{Competing interests None.}

Ethics approval Ethics approval was provided by the ethics committe of the Centre hospitalier affilié universitaire de Québec.

Provenance and peer review Commissioned; not externally peer reviewed. 


\section{REFERENCES}

1. Nagelkerke NJ, Jha P, de Vlas SJ, et al. Modelling HIV/AIDS epidemics in Botswana and India: impact of interventions to prevent transmission. Bull World Health Organ 2002;80:89-96.

2. Williams JR, Foss AM, Vickerman $P$, et al. What is the achievable effectiveness of the India AIDS Initiative intervention among female sex workers under target coverage? Model projections from southern India. Sex Transm Infect 2006:82:372-80.

3. Bureau of the Census US. HIV/AIDS Surveillance Data Base at the Population Division. 2006. http://www.census.gov/ipc/www/hivaidsd.html.

4. Talbott JR. Size matters: the number of prostitutes and the global HIV/AIDS pandemic. PLOS ONE 2007;2:e543.

5. Avahan-The India AIDS Initiative. The business of HIV prevention at scale. New Delhi, India: Bill \& Melinda Gates Foundation, 2008. http://www.gatesfoundation.org/ avahan/Documents/Avahan_HIVPrevention.pdf.

6. Chandrasekaran $\mathbf{P}$, Dallabetta G, Loo V, et al. Containing HIV/AIDS in India: the unfinished agenda. Lancet Infect Dis 2006;6:508-21.

7. National Interim Summary Report (October 2007), Integrated Behavioural and Biological Assessment (IBBA), Round 1 (2005-2007): Indian Council of Medical Research \& Family Health International.

8. Use it or lose it: How Avahan used data to shape its HIV prevention efforts in India. New Delhi, India: Bill \& Melinda Gates Foundation, 2008. http://www.gatesfoundation. org/avahan/Documents/Avahan_UseltOrLooselt.pdf.

9. Census of India, Office of Registrar General and Census Commissioner, India. http:// censusindia.gov.in/vital statistics/Vital Rates/Vital rates.aspx.

10. O'Neil J, Orchard T, Swarankar RC, et al. Dhandhā, dharma and disease: traditional sex work and HIV/AIDS in rural India. Soc Sci Med 2004;59:851-60.

11. Celum C, Levine R, Weaver $\mathrm{M}$, et al. Genital herpes and human immunodeficiency virus: double trouble. Bull World Health Organ 2004;82:447-53.

12. Corey L, Wald A, Celum CL, et al. The effects of herpes simplex virus-2 on HIV-1 acquisition and transmission: a review of two overlapping epidemics. J Acquir Immune Defic Syndr 2004;35:435-45.

13. Freeman EE, Weiss HA, Glynn JR, et al. Herpes simplex virus 2 infection increases HIV acquisition in men and women: systematic review and meta-analysis of longitudinal studies. AIDS 2006;20:73-83.

14. Mbopi-Keou FX, Gresenguet G, Mayaud P, et al. Interactions between herpes simplex virus type 2 and human immunodeficiency virus type 1 infection in African women: opportunities for intervention. J Infect Dis 2000;182:1090-6.

15. Weiss HA, Buve A, Robinson NJ, et al. The epidemiology of HSV-2 infection and its association with HIV infection in four urban African populations. AIDS 2001;15 (Suppl 4):S97-108.

16. Leclerc PM, Garenne M. Commercial sex and HIV transmission in mature epidemics: a study of five African countries. Int J STD AIDS 2008;19:660-4.
17. Vandepitte J, Lyerla R, Dallabetta $G$, et al. Estimates of the number of female sex workers in different regions of the world. Sex Transm Infect. 2006;82 (Suppl 3):iii18-25.

18. http://www.africansagainstaids.org, (accessed 5 July 2007)

19. Buvé A, Alary M, Vandepitte J. The fatal attraction of ecologic studies PLoS 01) ne [21]. 2007; http://www.plosone.org/annotation/getCommentary.action?target=info\% 3Adoi\%2F10.1371\%2Fjournal.pone.0000543).

20. International Institute for population Sciences (IIPS). District Level Household Survey (DLHS-2), 2002-04: India. Mumbai: IIPS, 2006. http://www.rchiips.org/pdf/ rch2/National Report_RCH-II.pdf.

21. Vadivoo S, Gupte MD, Adhikary R, et al. Appropriateness and execution challenges of three formal size estimation methods for high-risk populations in India. AIDS 2008;22 (Suppl 5):S137-48.

22. Kumar R, Jha P, Arora $\mathrm{P}$, et al. Trends in HIV-1 in young adults in south India from 2000 to 2004: a prevalence study. Lancet 2006;367:1164-72.

23. Alary $\mathbf{M}$, Lowndes CM. The central role of clients of female sex workers in the dynamics of heterosexual HIV transmission in sub-Saharan Africa. AIDS 2004:18:945-7.

24. Lowndes $\mathbf{C M}$, Alary $\mathrm{M}$, Meda $\mathrm{H}$, et al. Role of core and bridging groups in the transmission dynamics of HIV and STIs in Cotonou, Benin, West Africa. Sex Transm Infect. 2002; 78(Suppl 1):i69-77.

25. Ramesh BM, Moses S, Washington R, et al. Determinants of HIV prevalence among female sex workers in four south Indian states: analysis of cross-sectional surveys in twenty-three districts. AIDS 2008;22(Suppl 5):S35-44.

26. Morgenstern H. Ecologic studies. In: Rothman KJ, Greenland S, Lash TL, eds Modern epidemiology. 3rd edn. Philadelphia: Lippincott-Williams \& Wilkins; 2008:511-31.

27. Bongaarts $\mathbf{J}$, Reining $P$, Way $P$, et al. The relationship between male circumcision and HIV infection in African populations. AIDS 1989;3:373-7.

28. Moses S, Bradley JE, Nagelkerke NJ, et al. Geographical patterns of male circumcision practices in Africa: association with HIV seroprevalence. Int J Epidemiol 1990;19:693-7.

29. Weiss HA, Quigley MA, Hayes RJ. Male circumcision and risk of HIV infection in sub-Saharan Africa: a systematic review and meta-analysis. AIDS 2000;14: 2361-70.

30. Auvert B, Taljaard D, Lagarde E, et al. Randomized, controlled intervention trial of male circumcision for reduction of HIV infection risk: the ANRS 1265 Trial. PLOS Med 2005;2:e298.

31. Bailey RC, Moses S, Parker CB, et al. Male circumcision for HIV prevention in young men in Kisumu, Kenya: a randomised controlled trial. Lancet 2007;369: 643-56.

32. Gray RH, Kigozi G, Serwadda D, et al. Male circumcision for HIV prevention in men in Rakai, Uganda: a randomised trial. Lancet 2007;369:657-66. 